\title{
ENFORMASYON SISTEMLERI YÖNETIMI PERSPEKTIFINDEN KURUMSAL ÖRGÜT KÜLTÜRÜ
}

\author{
Ezgi Dinçerden*
}

\section{ÖZET}

Bilişim disiplininin temel kavramlarından biri olan enformasyon ve buna bağlı Enformasyon Sistemleri (ES), özellikle orta ve büyük-ölçekli kurumlar açısından gitgide önem kazanmakta ve Bilişim Teknolojileri (BT) gelişimi doğrultusunda hızla şekillenmeye devam etmektedir. Illetişim Teknolojileri araçlarının da katkısıyla bu sistemler; kuruma özgü veri ve enformasyon yönetimine olanak sağlamakla birlikte, aynı zamanda kurum çalışanlarımın sorumlu olduğu iş süreçleri ve iş iletişiminde de etkili olmaktadır. Bu çalışmanın amacl; takibi gittikçe zorlaşan ve yenilikçi bakış açısı gerektiren Bilişim ve İletişim Teknolojileri de göz önünde bulundurulduğunda, kurumlarda örgüt kültürü bağlamında sonkullanıcı olarak kurum çalışanları ile ES işleyişi arasındaki etkileşimi ve ayrıca BT yönetimi boyutuyla organizasyon davranışları ve alışkanlıklarının yönelimini açılamaktır.

Anahtar Kelimeler: Bilişim teknolojileri, enformasyon sistemleri, bilişim, enformasyon, inovasyon, organizasyonel kültür, kurumsal örgüt kültürü, kurum kültürü, kurumsal kültür

\section{ORGANIZATIONAL CULTURE IN ENTERPRISES FROM A PERSPECTIVE OF INFORMATION SYSTEMS MANAGEMENT}

\begin{abstract}
Information which is one of the basic issue of Informatics discipline and accordingly Information Systems (IS) are becoming increasingly important especially in the middle and big-scale enterprises and they are proceeding to progress in accordance with Information Technologies (IT) development. These systems enable to manage the institutional data and information, meanwhile they can also influence on business processes that company employees are responsible for and business communication through also tools of Communication Technologies. The porpose of this study is to explain interaction between corporate employees as end-user and IS process in the context of organizational culture in the enterprises, and also orientation of organizational behaviours and habits in dimension of IS management considering Information and Communication Technologies that are difficult to follow and require an innovational point of view.
\end{abstract}

Keywords: Information technologies, information systems, informatics, information, innovation, organizational culture, corporate culture

\section{GíRiş}

Günümüzde veri, enformasyon ve bilgi kavramlar1; birey ve toplulukların sosyal yaşamından kurum, işletme, firma gibi daha çok ekonomik alanda etkili olan kuruluşların sürdürülebilirliğini sağlamasına kadar hemen her alanda aktif rol

* Arş. Gör. Dr., Marmara Üniversitesi İletişim Fakültesi 
oynamaktadır. Bilişim disiplinin temel kavramları arasında yer alan veri, büyük veri (big data), enformasyon ve bilgi; araştırma konusu olarak oldukça geniş yelpazeye sahip olmakla beraber, bunların genellikle yazılım, donanım ve ağ yapılandırma gibi teknik öğelerden oluştuğu düşünülmektedir. Dolayısıyla Enformasyon Sistemleri (ES) söz konusu olduğunda; bilişim uzmanları tarafından genellikle veritabanı yönetim sistemleri (database management systems), veri ambarlama (data warehousing), veri madenciliği (data mining), yapay sinir ağları (artificial neural networks), karar destek sistemleri (decision support systems), iş zekâsı sistemleri (business intelligence systems) gibi teknik uzmanlık alanları akla gelmektedir.

Ancak bu sistemlerin kurulumu, işlemesi ve sürdürülebilmesi; teknik yapı ve uygulamaların ötesinde insan faktörüne de ihtiyaç duymaktadır. Son yıllarda hızla gelişen Bilişim Teknolojilerine (BT) uyum sağlayabilmeyi başarmak; kurumların sadece teknik kabiliyeti ve bilgilerini geliştirmekle yükümlü çalışanlarını değil, buna ek olarak bu veri ve enformasyonu kullanacak insan kaynaklarını da geliştirmesiyle mümkün olabilmektedir. Dolayısıyla bir kurumda ES oluşturmada teknik gereksinimlerin yanı sıra, enformasyon sistemi işleyişi sürecinde bazı durumlarda göz ardı edilebilen as-üst koordinasyonundan çalışan ilişkilerine, personel ihtiyaçlarından kurum yapısına dayanan bazı sosyal, psikolojik ve ekonomik etmenler de ES entegrasyonu ve adaptasyonunda etkili olmaktadır.

Bu açıdan bakıldığında, Bilişim ve İletişim Teknolojileri aracılığıyla ES'ye işlevsellik kazandırma konusunda son kullanıcı (end user) olarak hassas rolü olan insan faktörünü göz ardı etmek mümkün değildir. Buna ek olarak, yine insan faktörü; bir kurumun enformasyon sistemini oluşturma, geliştirme ve sistemin mümkün olduğunca sorunsuz işleyişin sağlanmasında geliştirici ve karar-verici olarak da karşımıza çıkmaktadır. Kuruma özgü sistem gereksinimlerinin karşılanması ve gelişim gidişatına yön verme gibi konularda aktif rol oynayan yönetici ve/veya karar-vericiler de bu süreçte ayrıca etkili olmaktadırlar. Ayrıca, kurum ölçeğine bağlı çalışan hacmi ve niteliği de ES yapısını şekillendirmede diğer önemli etkendir. Başka bir ifadeyle, kuruma özgü enformasyon sistemi kurulumu ve işleyişinde; kurumun büyük, orta veya küçük-ölçekli olması ile yakından ilgili olan organizasyonel kültür kavramının önem derecesi de gittikçe artmaktadir.

Bu noktada kurum ölçeğine bağlı tüm çalışanlarının bireysel değerleri, alışkanlıkları ve bireysel davranışlarının ön plana çıktığı kurumsal örgüt kültürü veya kurum kültürü (organizational culture, corporate culture) kavramının önemi daha belirgin hale gelmektedir. Kurumsal kültür ile ilişkili özellikle bilgi çalışanlarının davranışları, alışkanlıkları ve değerleri; organizasyona yönelik iş süreçleri, takım çalışması, iş iletişimi, zaman yönetimi ve benzeri fonksiyonların işleyişinde, kuruma avantaj ve/veya dezavantaj olarak geri dönebilmektedir. 
Ayrıca belirtmek gerekir ki; bu çalışmada Bilişim Sistemleri daha geniş anlam ifade ettiği kabul edilmekle birlikte, makale konusu kapsamında bilişim sistemi kastedilirken Enformasyon Sistemleri (ES) terimi kullanılmıştır. Ek olarak, sürekli ve hızlı gelişim gösteren bazı teknolojik terimlerin, ortak bir dil oluşturmayı kolaylaştıracak şekilde Türkçe'ye çevrilmesine de özen gösterilmiştir. Bunun yanı sıra başka bir çalışma kısıtı da, örgüt kültürü kavramının pek çok disiplinde yer alması ve geniş kapsamlı olması sonucu, çalışmada bu kavrama; onun ES ile ilgisini açılamak üzere yer verilmesidir.

Dolayısıyla bu çalışmada, özellikle orta ve büyük ölçekli kurumlara özgü ES işleyişinde tüm kurum çalışanlarını ilgilendiren kuruma yönelik örgüt kültürü üzerinde durulmuştur. Bununla birlikte çalışmanın amacı; kurum veya firmaların iç ve dış çevreleri ile iletişim kanalları da dikkate alındığında, günümüzde kavramsal olarak anlam karmaşıklığı gözlemlenen bilişim kavramının, eksikliği gitgide daha çok farkına varılan kavramsal ve sosyolojik boyutunu da güçlendirmektir.

\section{KURUMSAL ÖRGÜT KÜLTÜRÜ KAPSAMI}

Disiplinlerarası anlam karmaşası olmaması açısından kısa bir açılama yapmakta fayda vardır. Bu çalışmada "kurumsal örgüt kültürü" olarak adlandırılması uygun görülen bu kavram; İngilizce veya Türkçe kaynaklarda organizasyonel kültür, kurum kültürü, örgüt kültürü, işletme kültürü ve benzeri ifadelerle de karşımıza çıkabilmektedir. Çalışmada tam anlamı verebilmek için kurumsal örgüt kültürü tanımlaması türetilmiş, ancak bazı yerlerde organizasyonel kültür, kurum kültürü ve kurumsal kültür ifadesi de kullanılmıştır.

Kültür; çeşitli disiplinlere göre farklı yönleri ve alt kültürleri içermekle birlikte, konu kapsamında genel bir çerçeve çizmek gerekirse; bir toplumdaki insanların yaşam amacı, dünya görüşleri, dil ve konuşma tarzları, "iyi" veya "kötü" anlayışları, tutumları, davranışları, inançları, "doğru"lar ve "yanlış"ları, insanlar arasındaki ilişkileri, yaşamın değerli olan yönleri, yetki ve sorumluluk anlayışları, zaman kavramına bakışları, giyim-kuşam ve görünüşleri, özgürlük ve bağımlılıkları, yasalara uygun davranışları, kişisel ve toplumsal çıkar ve benzeri konularda değer, anlayış, simge, sembol ve bakış açılarının toplamı (Koçel 2013: 135-136) olarak özetlenebilir.

Kurum veya işletmelerde örgüt kültürünü ise genel hatlarıyla bir terimler, formlar, kategoriler ve imajlar sistemi (Pettigrew 1979: 570, Green ve Cluley 2014: 1344) olarak tanımlayabiliriz. Başka bir ifadeyle örgüt kültürü; insanların alışılmış şekilde diğer kişiler, görevleri ve geniş çevre ile nasıl ilişki kurduklarını şekillendiren bir varsayımlar ve inançlar seti (Schein 2010 akt. Canato ve Ravasi 2015: 75) olarak tanımlanmakla birlikte, Şekil 1'de görüldügü gibi kurumsal veya organizasyonel kültürü kavramsal şekilde (Canato ve Ravasi 2015: 80) göstermek mümkündür. 


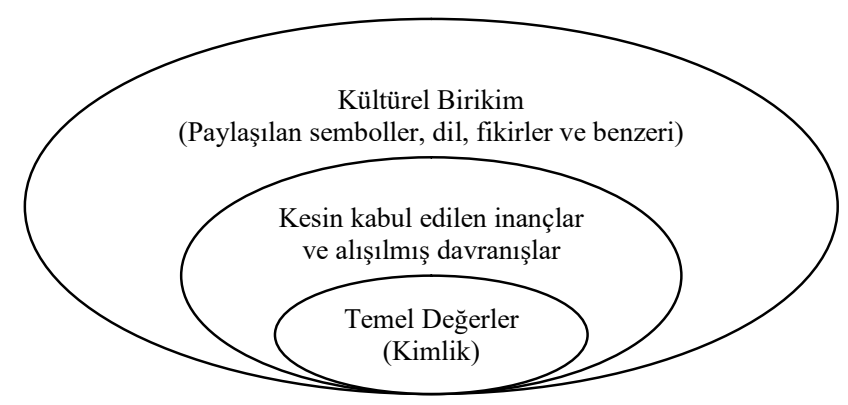

Şekil 1. Kurumsal Örgüt Kültürü: Değişim İçin İçselleştirme ve İşlenebilirlik Derecesine Dayalı Yeniden Kavramsallaştırma

Kurumlarda örgütsel performansın kültür ile ilişkilendirilmesinde, kültür değerlemesi üzerine en popüler olarak gösterilebilecek "yarışan veya rakip değerler çerçevesi" (competing values framework) yaklaşımı, aşağıdaki gibi sınıflandırılabilmektedir (Denison ve Spreitzer 1991 akt. Gregory ve ark. 2009: 673-674):

- Grup Kültürü: Grup kültürü, yüksek esneklik ve içsel odaklanmaya uyum sağlamakla birlikte, bu kültürde gruba sıkıca bağlı hale gelen grup dinamikleri çok önemlidir. Ayrıca bu kültürler; dayanışma ve katılımcı karar-vermeye değer vermekte ve ortak çalışanlar arasında destek olmaya saygı duymaktadır. Yöneticiler bu değerleri; yetkilendirme veya yetki verme, danışmanlık yapma ve takım çalışmasına destek olma yoluyla desteklemekte ve güçlendirmektedirler.

- Gelişimsel Kültür: Bu kültür; esneklik olarak dışsal odağa önem vermektedir. Bu kültürel yöneltme; organizasyon veya kurumun büyümesine yönelik istekleri ve umutları için bir değişim ve adaptasyondur. Liderlik; organizasyon için yeni kaynaklar elde etme umudu olan çalışanların girişimci risklerini desteklemekte ve kreatif yaklaşımlarına ilham vermektedir.

- Rasyonel Kültür: Bu kültür türü; dışsal-odaklı kontrole vurgu yapmakla birlikte, davranışların dişsal çevreye doğru yönlendirilmesi esnasında, çalışan hareketlerini kontrol etme biçimini temsil eden amaçlar olarak önemli bir değeri teşkil etmektedir. Bu kültürler iyi yapılandırılmış ölçütlere yönelik verimlilik, başarı ve rekabete değer verme eğilimi göstermektedir.

- Hiyerarşik Kültür: Kurum içi-odakl1 kontrolü vurgulayan bu kültür; içsel etkinliği ön plana çıkaran tekbiçimlilik ve koordinasyonu ifade etmektedir. Sıkı veya katı yönergeler ve kurallar; davranışları düzenlemekte ve çalışanlar bu değişmez sayılabilecek çevrede iş yapma güvenliğine değer vermektedirler.

- Dengeli Kültür: Dengeli kültür; birbirine sıkıca tutunan her bir rakip değerler çerçevesi kültür alanı ile ilişkili değerleri ifade etmekte (Quinn 1988 akt. Gregory ve ark. 2009: 674) ve çevresel değişimleri yönetmede belirgin bir avantaj sağlamaktadır. 
Bir başka kurumsal kültür sınıflandırılmasının gösterildiği Tablo 1'deki (Quinn ve McGrath akt. Ngwenyama ve Nielsen 2003: 102) matriste ise, kurumsal bakış açılarına göre kültür türlerinin işlevleri ayrıntılı şekilde tanımlanmaktadır. Tabloda da açıkça ifade edildiği gibi kurum kültür türlerini kurumsal işlevlere göre incelediğimizde, ES perspektifinden kurumsal örgüt kültürüne en çok uyan bakış açılarının; değişime, yeniliklere açık ve esneklik özellikleri ile uzlaşımsal ve gelişimsel kültür türleri olduğu sonucuna varılabilir.

Tablo 1. Kurumsal Örgüt Kültüründe Rekabet Eden Değerler

\begin{tabular}{|c|c|c|c|c|}
\hline Bakış Açısı & Hiyerarşik & Rasyonel & Uzlaşımsal & Gelişimsel \\
\hline $\begin{array}{l}\text { Organizasyonel } \\
\text { (Örgütsel) Or- } \\
\text { yantasyon }\end{array}$ & $\begin{array}{c}\text { Durağanlık ve } \\
\text { kontrol }\end{array}$ & $\begin{array}{l}\text { Verimlilik ve } \\
\text { etkinlik }\end{array}$ & $\begin{array}{c}\text { Kohezyon } \\
\text { (uyuşma) ve } \\
\text { moral }\end{array}$ & $\begin{array}{l}\text { Esneklik, adapte } \\
\text { olabilirlik ve ha- } \\
\text { zır bulunma }\end{array}$ \\
\hline $\begin{array}{l}\text { Kurumsal Ör- } \\
\text { güt Amaçları }\end{array}$ & $\begin{array}{l}\text { Regülasyon } \\
\text { uygulaması }\end{array}$ & $\begin{array}{c}\text { Amaçları izle- } \\
\text { me }\end{array}$ & $\begin{array}{l}\text { Grup de- } \\
\text { vamlilığ1 }\end{array}$ & $\begin{array}{l}\text { Büyüme ve geli- } \\
\text { şim }\end{array}$ \\
\hline $\begin{array}{l}\text { Kurumsal Ör- } \\
\text { güt Yapısı }\end{array}$ & $\begin{array}{l}\text { Rutin görevler } \\
\text { ve teknoloji; } \\
\text { formal (resmi) } \\
\text { kurallar ve } \\
\text { politikalar }\end{array}$ & $\begin{array}{l}\text { Karmaşık gö- } \\
\text { revler; uzman- } \\
\text { lığa dayalı so- } \\
\text { rumluluklar }\end{array}$ & $\begin{array}{c}\text { Karmaşık } \\
\text { görevler; } \\
\text { işbirlikçi } \\
\text { (ortak) ça- } \\
\text { lişma grup- } \\
\text { ları } \\
\end{array}$ & $\begin{array}{l}\text { Karmaşık görev- } \\
\text { ler; işbirlikçi (or- } \\
\text { tak) çalışma } \\
\text { grupları }\end{array}$ \\
\hline Güç Tabanı & $\begin{array}{c}\text { Kurumsal } \\
\text { kural \& pro- } \\
\text { sedür (izlek) } \\
\text { bilgisi } \\
\end{array}$ & $\begin{array}{l}\text { Yetkinlik (ye- } \\
\text { terlilik) }\end{array}$ & $\begin{array}{l}\text { İlişki kurma } \\
\text { yeteneği }\end{array}$ & Değerler \\
\hline Karar Verme & $\begin{array}{l}\text { Yukarıdan } \\
\text { aşağı resmi } \\
\text { bildiriler }\end{array}$ & $\begin{array}{c}\text { Amaç- } \\
\text { merkezli, sis- } \\
\text { tematik ve } \\
\text { analitik }\end{array}$ & $\begin{array}{l}\text { Katılımc1, } \\
\text { bilinçli }\end{array}$ & Organik, sezgisel \\
\hline Liderlik Stili & $\begin{array}{l}\text { Üstünlük, } \\
\text { tutucu, tedbir- } \\
\text { li }\end{array}$ & $\begin{array}{l}\text { Oransal başarı- } \\
\text { lı, amaç yöne- } \\
\text { limli }\end{array}$ & $\begin{array}{c}\text { Takım kuru- } \\
\text { cu; ilgili, } \\
\text { destekleyici }\end{array}$ & $\begin{array}{c}\text { İdealist, risk- } \\
\text { yönelimli, yetki- } \\
\text { lendirme }\end{array}$ \\
\hline Uyumluluk & $\begin{array}{c}\text { Gözlemleme } \\
\text { ve kontrol }\end{array}$ & $\begin{array}{c}\text { Sözleşmeli } \\
\text { anlaşma }\end{array}$ & $\begin{array}{c}\text { Sürece bağl1- } \\
\text { l1k }\end{array}$ & Değerlere bağlılık \\
\hline $\begin{array}{l}\text { Üye Değerle- } \\
\text { mesi }\end{array}$ & $\begin{array}{c}\text { Kurallara } \\
\text { bağl1 }\end{array}$ & $\begin{array}{c}\text { Verimlilik se- } \\
\text { viyesi } \\
\end{array}$ & İlişki niteliği & Çaba yoğunluğu \\
\hline $\begin{array}{l}\text { Değişim için } \\
\text { Oryantasyon }\end{array}$ & $\begin{array}{c}\text { Dirençli } \\
\text { (mevcut du- } \\
\text { rumu sür- } \\
\text { dürme yöne- } \\
\text { limli) }\end{array}$ & $\begin{array}{l}\text { Amaç-devamlı } \\
\text { değişime açık }\end{array}$ & $\begin{array}{l}\text { Değişime } \\
\text { açık }\end{array}$ & $\begin{array}{l}\text { Değişim büyü- } \\
\text { menin bir parçası } \\
\text { olarak benim- } \\
\text { senmekte }\end{array}$ \\
\hline
\end{tabular}

Şunu da vurgulamak gerekir ki; son yıllarda kurumsal faaliyetlerin BT'ye adaptasyonunda kurumların değişime reaksiyonları ön plana çıkmaktadır. Yine örgüt kültüründe kuruma özgü organizasyon davranışları ve normların yanı sıra, or- 
ganizasyon veya kurum yapısı da göz önünde bulundurulmalıdır. Bu bağlamda kurum ölçeği, kurumsal kültürün bireyleri etkileme alanı olarak doğru orantılı bir gidişat izlemektedir. ES ile ilgili diğer bir önemli faktör de kurumun amaçlarına yönelik değerler olmakla birlikte, gelişim ve büyüme odaklı firmalar; BT'yi de yakından takip etme ve ES'yi ona adapte etmeye yönelik bir kurum politikası tercih etmektedir.

Organizasyonel kültürünün ES yönetimi ile ilgili kapsamından bahsettikten sonra, takip eden başlık altında yine kuruma özgü ES temel bileşenleri ve buna bağlı ES teknoloji ve/veya uygulamalarını kullanmakla sorumlu olan kurum çalışanlarının, yöneticilerin ve işverenlerin kurum kültürüne bağlı alışkanlıkları arasındaki bağlantı açıklanmıştır.

\section{ENFORMASYON YÖNETIMİ BOYUTUYLA ÖRGÜT KÜLTÜRÜ}

Kurumsal enformasyon bir firma veya organizasyonun ihtiyacı olan ve/veya olabilecek nitelikli bilgiye ulaşmak amacıyla, kurum verisinin toplanması, depolanması ve işlenmesi sonucu veride meydana gelen dönüşümü temsil etmektedir. Söz konusu işleyiş sırasında oluşabilecek aksaklıkların düzeltilmesi, bakımı, kontrol ve test edilmesi gibi kurulum sonrası destekler de bu sürecin içinde düşünülmelidir. İşte kaliteli veya nitelikli bilgiye erişimin temeli olarak özetleyebileceğimiz bu süreçler bütünü, bir enformasyon sistemi olarak tanımlanabilir. Başka bir ifadeyle, ES herhangi bir kurum veya organizasyon verisinin nitelikli enformasyon ve nihayetinde ihtiyaç duyulan bilgiyi elde etmeyi sağlayan ve ihtiyaca göre özelleştirilebilen sistemlerdir.

Biraz daha ayrıntıya inersek, bir enformasyon sisteminin temel bileşenlerini girdi, çıktı, teknoloji, modeller, veritabanı ve kontrol olarak gruplandıran Burch ve Grudnitski (1990: 45), buna bağlı tasarım güçlerini ise; entegrasyon (bütünleşme), kullanıcı/sistem arayüzü, rekabet güçleri, enformasyon kalitesi ve kullanılabilirliği, sistem gereksinimleri, veri işleme gereksinimleri, kurumsal (organizasyonel) faktörler, mali-etkinlik gereksinimleri, insan faktörü ve fizibilite gereksinimleri olarak sıralamıştır. Kurumsal kültürün bu tasarım güçlerinin tamamını etkilediğini söylemek mümkündür.

Bilişim disiplinin temel kavramları olan veri, enformasyon ve bilgi piramidinde (Frické 2009: 131, Vercellis 2009: 6); girdi olarak verinin toplanmas1, depolanmas1, işlenmesi ve nihayetinde nitelikli bilgiye dönüşümünde iş zekâsı (business intelligence) tekniklerinden de (Moss ve Atre 2003, Vercellis 2009, Howson 2014, Dinçerden 2017) faydalanan ES, günümüzde özellikle karar-verici yöneticiler açısından doğrudan etkilidir. Bu açıdan bakıldığında bu sistemler, kurum yönetiminde ve dolayısıyla kurum kültüründe önemli rol oynamaktadır. Yine genel hatlarıyla bir enformasyon sistemini oluşturma aşamalarının fizibilite, analiz, tasarım, uygulama ve devamlılık için bakım olarak (Yeates ve Wakefield 2004: 131) kabul edersek, her aşamada teknoloji odaklı işgücü, kullanıcı odaklı kararverici ve dolayısıyla insan faktörünün önemi karşımıza çıkmaktadır. 
Bir kurumda kültür kavramı, iş süreçleri ve BT'ye bağlı değişimin başarılı olabilmesi için sıklıkla kritik bir öğe olarak (Cooper 1994: 17) tanımlanmaktadır. Bireyler, onların değerlerini etkileyen pek çok kültürel gruplara ait olup, çeşitli kimliklere sahiptirler. Dolayısıyla, kültürel bir grupta; tüm grup üyelerinin benzer düşünüp hareket etmelerinin homojen olması mümkün değildir. Söz konusu farklılıklara rağmen, kültürel bir gruptaki üyeler arasındaki ortak özellikler; paylaşılan değerlere dayanmaktadır. Bu kapsamda ES'ye bağlı İş Süreci Yönetimi (Business Process Management) açısından ele aldığımızda, bu süreçleri aşağıda sıralanan kavramlar ile tanımlamak; ES açısından kurum kültüründe etkili faktörlerin ortaya konması bakımından açıklayıcı olacaktır (Schmiedel ve ark. 2014: 44):

- Müş̧teri Yönelimleri: Süreç çıktısı alıcılarının ihtiyaçlarına karşı proaktif ve duyarli tutum.

- Mükemmellik: Devam eden gelişime yönelik oryantasyon ve üstün süreç performansını başarmak için inovasyon.

- Sorumluluk: Süreç amaçlarına bağl1lık ve süreç kararları için hesap verebilirlik.

- Takım Çalışması: İşlevler arası işbirliğine yönelik olumlu bir tutum.

Özellikle kâr-amaçlı kurumların işleyişinde aktif rol oynayan BT ve ES uygulamalarının en az hata ile yönetilebilmesi ve işleyebilmesi için, üst-düzey yöneticilerden (Chief Executive Officer-CEO) operasyonel çalışanlara kadar tüm kurum üyelerinin uyum içinde olması gerekmektedir. Bu noktada da kültürel işlevsellik; sadece alıcı veya müşteriler açısından değil, aynı zamanda ES araçları arasında sayılabilecek Kurumsal Kaynak Planlama (Enterprise Resource Planning-ERP), Customer Relationship Management-CRM), Tedarik Zinciri Yönetimi (Supply Chain Management-SCM) gibi uygulamaları kullanan operasyonel ve yönetimsel düzeydeki çalışan grupları bakımından da göz önüne alınmalıdır.

BT kullanımı ve ES uygulamalarının örgüt kültürü ile ilişkisinde en önemli etmenlerden biri de inovasyon (yenileşim) faktörüdür. Şekil 2'de gösterildiği gibi Schein'ın (1992) organizasyonel kültürün çok-katmanlı modelinden yola çıkılarak başarı, açıklık ve esneklik, içsel iletişim, yeterlilik ve profesyonellik, işlevler arası işbirliği, sorumluluk, değerleme, risk alma gibi değer boyutlarını (Hogan ve Coote 2014: 1612) içeren örgüt kültürünün inovasyon odaklı derecelendirmesi gösterilmektedir. Buna göre BT açısından yenilikçi çalışan davranışları doğrultusunda, ES ile kurumsal örgüt kültürü arasındaki etkileşim açıkça görülmektedir. 
Çok Fazla Görülebilir

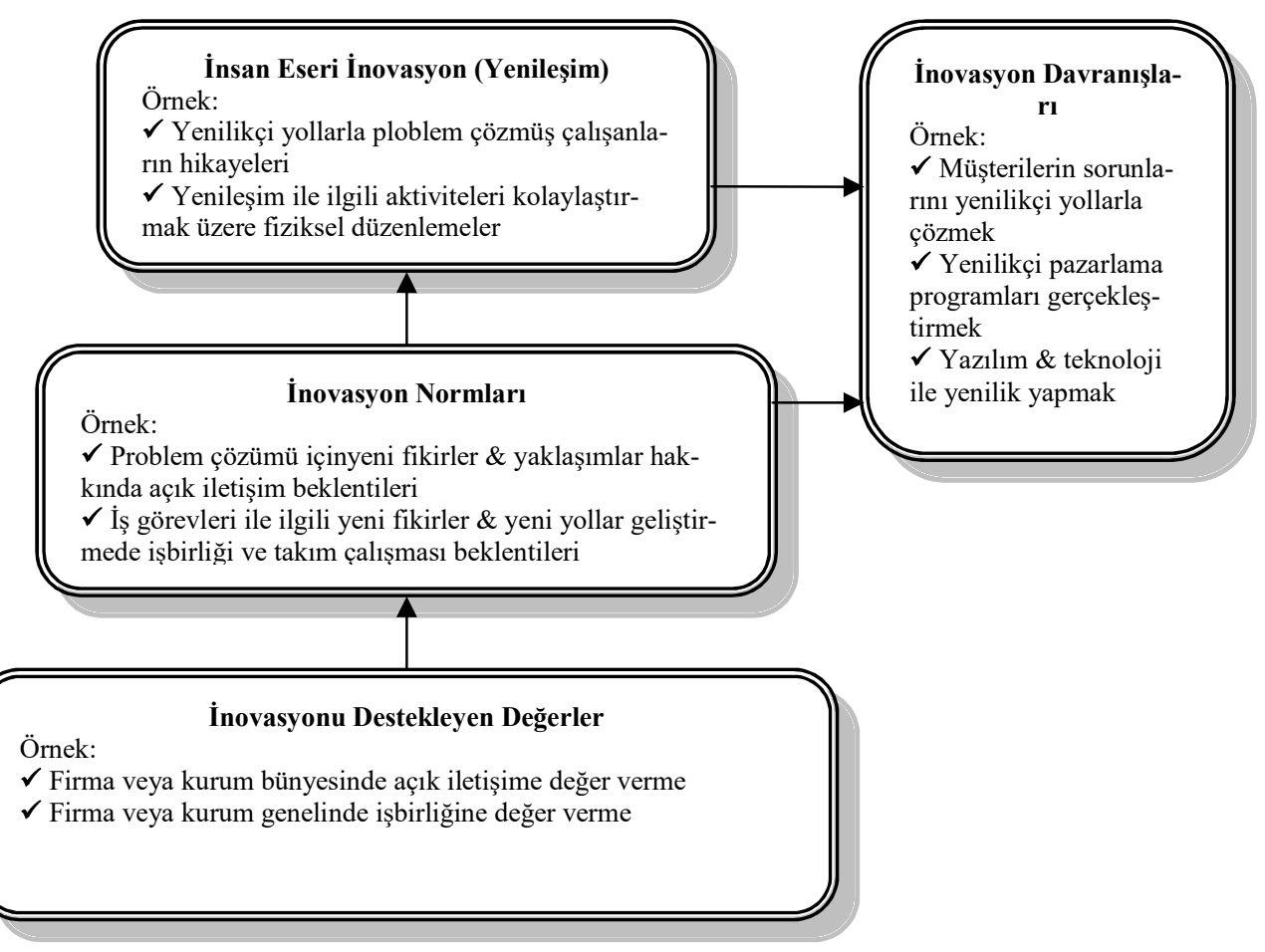

Şekil 2. Schein'ın Yenileşimi Destekleyen Kurumsal Örgüt Kültürü Katmanları

Bir enformasyon sisteminde yer alan ve/veya alabilecek her bir öğe ve safhanın ayrı bir uzmanlık gerektirdiği göz önüne alındığında, ES; bünyesinde oldukça kapsamlı araştırma konularını barındırmaktadır. Bu süreçleri yönetmek için; insan özellikleri bakımından hem gerektiğinde kendini geliştirebilecek teknik altyapıya sahip olma yetisi, hem de teorik bilgi birikimi gerekliliği kaçınılmazdır. $\mathrm{Bu}$ açıdan bakıldığında kurum bünyesinde gerek yönetici davranışları, gerek karar-vericiler ve gerek de son kullanıcılar açısından örgüt kültürü hareketleri; oluşturulan ve işlerlik kazanan enformasyon sistemi ile uyum sağlamayı başarabilmelidir.

\section{SONUÇ}

BT'nin hızla ivme kazanmasına paralel olarak, geliştirilmesinin önemi gittikçe daha da belirginleşen ES ve buna bağlı sistem uygulamaları, günümüzde özellikle kâr-amaçlı kurumlar açısından lüks olmaktan çıkıp bir zorunluluk haline gelmiştir. Firmalara rekabet edebilirlik, yatırımlarda geri dönüş (Return on Investment), maliyet düşürme, dengeli bütçe ve tahminleme, kâr oranlarını arttırma gibi stratejik amaçlar açısından da kritik avantaj sağlayabilen (Dinçerden 2016: 60) bu sistemler; müşteri veya alıcı ihtiyaçlarını karşılamak üzere etkin bir aracı olmasının ötesinde üretim, pazarlama, bütçe planlama, finans-muhasebe, 
insan kaynakları, lojistik gibi kurum birimlerinin entegrasyonunda da verimli etkileşimi sağlayabilmektedir. Bu açıdan ele alındığında, kurum bünyesindeki çalışanlar bakımından ön plana çıkan organizasyon davranışları ve alışkanlıkları, kurum içindeki işleyişte ve kuruma özel enformasyon sisteminin kullanımında oldukça etkili olmaktadır.

Sonuç olarak kurum bünyesinde çalışan takım üyelerini kapsayan çeşitli bireysel tutum ve kültürel kimlikler; kurum veya kurumsal örgüt kültürünü oluşturma ve yönlendirmede etkin bir rol üstlenmekle birlikte, organizasyon bünyesinde ES ve kurumsal örgüt kültürünü ilişkisi, insan faktörü işlevleri bakımından aşağıdaki gibi dört ana gruptan oluşan bir sınıflandırma ile özetlenebilir:

- Yöneticiler: ES oluşturma, uygulama ve gelişimi safhalarının hemen her aşamasında söz sahibi olan kurum yöneticileri, özellikle BT gelişimine açık olmalı, ayrıca inovasyon (yenilik, yenileşim, yenileşme), takım çalışmasında grup üyelerini yetkilendirme, onlara girişimcilik fırsatı verme gibi konularda destek olabilecek vizyona sahip olmalıdırlar.

- Enformasyon Sistemi Geliştirici ve Analistleri: Kuruma özgü veri, büyük veri ve enformasyonun en etkin ve verimli şekilde işlerlik kazanması amacıyla kurumsal örgüt kültürü faktörünü de dikkate almalıdır. Bir enformasyon sistemi, sistem kullanıcılarından en yüksek verimi alabilmek için mevcut kurum kültürü değerleri ve alışkanlıklarına mümkün olduğunca uyum sağlayabilmesine yönelik bazı eklentiler veya geliştirmeler yapmaya açık olacak şekilde tasarlanmalıdır.

- Enformasyon Sistemi Son-Kullanıcıları: ES ve BT bağlamında kurum-içi iş akışlarının sağlıklı şekilde işlemesi ve ES kullanımında kolaylık sağlama açısından dikkate alınması gereken sistem son-kullanıcı faktörü, kurum veya firmalarda kurumsal örgüt kültürü etkilerinin en güçlü olduğu grup olarak kabul edilmelidir. Dolayısıyla sistem kullanıcılarının, bir parçası olduğu örgüt kültürünü benimsemesi, ona uyum sağlamak için çaba göstermesi, yanlış kabul ettiği noktaları açıklamak üzere değişimi reddetmeden önce uygun bir yöntemle iletişim kurmayı denemesi ve kullanıcı olarak yeniliklere açık olması gerekmektedir.

- Alıcı ve/veya Müş̧teriler: Kurumsal kültür ile doğrudan bağlantılı olmayan, ancak kurum kültürüne dolaylı yoldan etkileyen müşteriler veya alıcılar, özellikle kurum stratejik amaçlarına ulaşmakta etkili faktörler arasında olmaları sebebiyle, benimsenen organizasyon kültürüne bağlı gerçekleştirilen iş süreci performansları hedefleri arasında yer almaktadırlar. Bu nedenle, onların talepleri de göz önüne alınmalı ve bu istek ve beklentiler de kurumsal kültür paralelinde sisteme entegre edilmelidir.

Böylece yukarıda belirlenen dört grup da, üzerinde durulan kıstasları dikkate alarak iş süreçlerindeki rolünü benimsediği takdirde, kurumsal iş iletişiminin sağlıklı işlemesi ve örgüt kültürü kaynaklı ortaya çıkabilecek sorunların çözümü açısından kurum olarak avantaj sağlayacaktır. Bununla birlikte, ES; kurumsal 
faaliyetlerin en az hata ile gerçekleştirilmesi ve kurumun geleceğine yönelik yol haritasını daha verimli şekilde belirlenmesi ve gerçekleştirilmesine destek olmaktadır. Dolayısıyla, BT gelişimi doğrultusunda ES için kaynak ayırma ve ES geliştirilmesine önem vermenin ötesinde, kurumsal örgüt kültürlerini bu sistemlere uyumlaştırmaya da özen gösteren kurumlar veya firmaların, orta ve uzun vadede sürdürebilirliklerini sağlamak üzere eşdeğerleri ve/veya rakiplerine göre çok daha avantajlı hale geleceği yadsınamaz bir gerçektir.

\section{KAYNAKÇA}

Burch J G and Grudnitski G (1990) Information Systems: Theory and Practice, John Wiley \& Sons, Inc., Canada.

Canato A and Ravasi D (2015) Managing Long-Lasting Cultural Changes, Organizational Dynamics, 44, 75-82.

Cooper R B (1994) The Inertial Impact of Culture on IT Implementation, Information \& Management, 27, 17-31.

Denison D R and Spreitzer G M (1991) Organizational Culture and Organizational Development: A Competing Values Approach, Research in Organizational Change and Development, 5, 1-21.

Dinçerden E (2015) The Effects of Business Intelligence on Strategic Management of Enterprises, Economics World: From Knowledge to Wisdom, 4 (2), 60-65.

Dinçerden E (2017) İş Zekâsı ve Stratejik Yönetim, Beta Basım A.Ş., İstanbul.

Frické M (2009) The Knowledge Pyramid: A Critique of the DIKW Hierarchy, Journal of Information Science, 35 (2), 131-142.

Green W and Cluley R (2014) The Field of Radical Innovation: Making Sense of Organizational Cultures and Radical Innovation, Industrial Marketing Management, 43, 1343-1350.

Gregory B T, Harris S G, Armenakis A A and Shook C L (2009) Organizational Culture and Effectiveness: A Study of Values, Attitudes, and Organizational Outcomes, Journal of Business Research, 62, 673-679.

Hogan S J and Coote L V (2014) Organizational Culture, Innovation, and Performance: A Test of Schein's Model, Journal of Business Research, 67, 16091621.

Howson C (2014) Successful Business Intelligence: Unlock the Value of BI \& Big Data, McGraw-Hill Education, USA.

Koçel T (2013) İşletme Yöneticiliği, Beta Basım A.Ş., İstanbul.

Li S H, Yen D C, Lu W H and Chen T Y (2014) The Characteristics of Infomation System Maintenance: An Empirical Analysis, Total Quality Management \& Business Excellence, 25 (3), 280-295. 
Moss L T and Atre S (2003) Business Intelligence Roadmap: The Complete Project Lifecycle for Decision-Support Applications, Pearson Education, Inc., Boston.

Ngwenyama O and Nielsen P A (2003) Competing Values in Software Process Improvement: An Assumption Analysis of CMM from an Organizational Culture Perspective, IEEE Transactions on Engineering Management, 50 (1), 100-111.

Quinn R E (1988) Beyond Rational Management, Josey-Bass, San Francisco.

Schein E H (1992) Organizational Culture and Leadership, Jossey-Bass Inc., San Francisco.

Schmiedel T, Brocke J V and Recker J (2014) Development and Validation of an Instrument to Measure Organizational Cultures' Support of Business Process Management, Information \& Management, 51, 43-56.

Vercellis C (2009) Business Intelligence: Data Mining and Optimization for Decision Making, John Wiley \& Sons Ltd., UK.

Yeates D and Wakefield T (2004) Systems Analysis and Design, Pearson Education Limited, London. 